Article

\title{
Converter-driven Stability Analysis of Power Systems Integrated with Hybrid Renewable Energy Sources
}

\author{
Jianqiang Luo ${ }^{1}$, Yiqing Zou ${ }^{1}$, and Siqi Bu ${ }^{1,2,3 *}$ \\ 1 Department of Electrical Engineering, The Hong Kong Polytechnic University, Kowloon, Hong Kong SAR. \\ jianqiang.luo@polyu.edu.hk; 18095429g@connect.polyu.hk. \\ 2 The Hong Kong Polytechnic University Shenzhen Research Institute, Shenzhen, China. \\ 3 Research Institute for Smart Energy, The Hong Kong Polytechnic University, Kowloon, Hong Kong SAR. \\ * Correspondence: siqi.bu@polyu.edu.hk
}

\begin{abstract}
Various renewable energy sources such as wind power and photovoltaic (PV) have been increasingly integrated into the power system through power electronic converters in recent years. However, power electronic converter-driven stability issues under specific circumstances, for instance, modal resonances might deteriorate the dynamic performance of the power systems or even threaten the overall stability. In this paper, the integration impact of a hybrid renewable energy source (HRES) system on modal interaction and converter-driven stability is investigated in an IEEE 16-machine 68-bus power system. Firstly, an HRES system is introduced, which consists of full converter-based wind power generation (FCWG) and full converter-based photovoltaic generation (FCPV). The equivalent dynamic models of FCWG and FCPV are then established, followed by the linearized state-space modeling. On this basis, converter-driven stability analyses are performed to reveal the modal resonance mechanisms of the interconnected power systems and the modal interaction phenomenon. Additionally, time-domain simulations are conducted to verify effectiveness of dynamic models and support the converter-driven stability analysis results. To avoid detrimental modal resonances, an optimization strategy is further proposed by retuning the controller parameters of the HRES system. The overall results demonstrate the modal interaction effect between external AC power system and the HRES system and its various impacts on converter-driven stability.
\end{abstract}

Keywords: Converter-driven stability; hybrid renewable energy source (HRES) system; modal resonance; full converter-based wind power generation (FCWG); full converter-based photovoltaic generation (FCPV)

\section{Introduction}

High penetration of converter-based power sources has become a popular trend nowadays for benefit of environment protection and society sustainability, especially the integration of wind power and photovoltaic (PV) solar energy in modern power systems [1]. The full converter-based wind generation (FCWG, e.g., permanent magnet synchronous generator (PMSG)) is more promising than doubly fed induction generators (DFIGs) in new wind power applications [2]. As for PV solar energy, several generic PV system models based on the Type 4 wind turbine generator model are introduced by Western Electric Coordinating Council (WECC) [3]. The PV generation is modeled as an inverterbased generator associated with a variety of active power control reactive power control options.

Renewable energy sources are interconnected to the power system via flexibly controlled power electronic converters that might produce new stability issues due to the dynamic interactions between converter-based generators and the power system, such as converter-driven stability, 
resonance stability [4]. Specially, oscillation issues could be induced by dynamic interaction between converters and external AC power systems. The sub-synchronous resonance (SSR) was observed in ERCOT of United States [5], Hebei province of North China [6], London blackout in United Kingdom [7], and sub-synchronous oscillation (SSO) in Xinjiang province of China [8]. Low frequency power oscillations are normally caused by the dynamic interaction between inter-connection of power grids and the fast-response automatic voltage regulators (AVRs). It is generally understood that the occurrence of the oscillations is due to the lack of damping of power systems electromechanical oscillation modes (EOMs) [9],[10]. An unusual transition in electromechanical dynamics is disclosed in [11], which indicates that an EOM may be dominated by FCWG dynamics and tuned into a quasiEOM when FCWG quasi-electromechanical state variables are actively participated. Reference [12] studies how system impedance and the parameters of the PLL affect the dynamic behavior and the stability limits of the converters in HVDC applications.

Furthermore, increasingly power electronic converter-interfaced renewable energy sources introduce a challenge for converter-driven stability of the overall system [13]. Although the interconnection of power electronic converter-interfaced renewable generators and conventional power systems enhances the overall flexibility and controllability[14-16], the dynamic interactions of both transmission and distribution systems becomes complicated [17-19]. Different from the traditional synchronous generators (SGs), converter-based renewable energy sources have a major impact on power system converter-driven stability. Reference [20] studies how the parameters of rotor current controllers have influences on the eigenvalues shift locus. Based on the dynamic modeling and analysis of traditional generators and converter-based DFIG, the impact on power system stability is the minimum under small scale penetration of wind power generations [21]. However, when the wind power penetration level increases, the converter-driven stability of the overall power systems may be greatly affected. Reference [22] concludes that the damping reduction of power system EOM may occur at weak interconnection lines and increased wind power penetration level. In multiple grid-interconnected PV generation systems, the coupling behavior between PLLs and near converters may make the system more vulnerable or even lose converterdriven stability $[23,24]$.

In this paper, a hybrid renewable energy source (HRES) system with FCWG and FCPV is considered in the same power system regarding their complex dynamic interactions with external AC power systems. The main contributions are listed as follows:

1) Detailed dynamic models of FCWG and FCPV, including PMSG, PV generation unit, DC/DC converter and the associated control system, DC-link, grid side converter (GSC) and associated control systems, synchronous reference frame phase locked loop (SRF-PLL) and the external AC power system are established. The linearized state-space models of each dynamic components as well as the entire closed-loop system are developed as the foundation of converter-driven stability analysis.

2) Based on above models, modal analyses are conducted with different wind power and PV solar energy penetration levels in the IEEE 16-machine 68-bus system. Peculiarly, critical open-loop FCWG oscillation mode (FOM) or FCPV oscillation mode (POM) is tuned to be approached to critical EOM, which is the necessary condition of open-loop modal resonance.

๑3) Open-loop and closed-loop modal analyses are compared. Modal resonance interaction in the examined system with different renewable energy penetration levels is evaluated to analyze the 
essential resonance mechanism, which provides a theoretical indication to alleviate the negative effect caused by strong modal resonance.

๑4) To circumvent the malignant modal resonance and to enhance the converter-driven stability, an optimization strategy is implemented to prevent potential modal resonance through carefully retuning the controller parameters of the HRES system. The overall converter-driven stability and dynamic performance of the entire system are improved thereafter.

\section{Hybrid Renewable Energy Source (HRES) System}

Wind power and PV solar energy have become prevalent renewable power sources and gradually possess a considerable share in modern power systems. Consequently, these renewable energy sources also induce a long lasting and complex impact on power system stability. In this section, an HRES system is introduced to cover different types of renewable energy and their complex modal interaction with external AC power systems.

\subsection{Configuration of FCWG}

The typical topology of an FCWG is depicted in Figure 1.

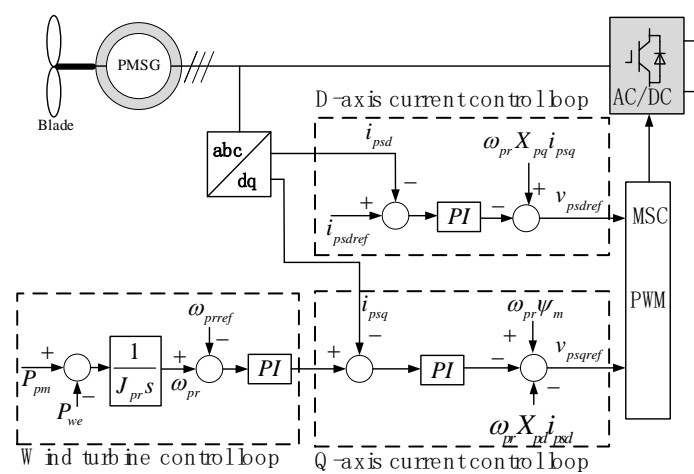

(a) Control configuration of Machine Side Converter

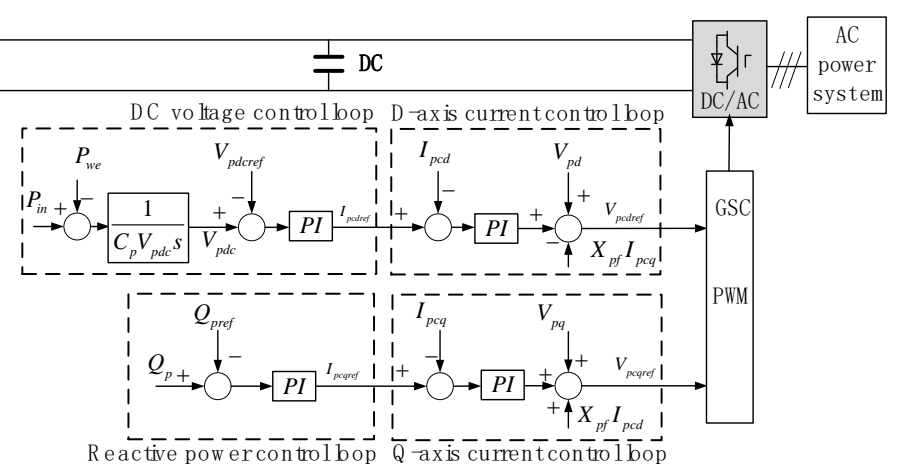

(b) Control configuration of Grid Side Converter

Figure 1. Physical configuration of an FCWG connected to the AC power system.

The FCWG consists of three parts: 1) The PMSG, the machine side converter (MSC) and the associated control system (as demonstrated in Figure 1(a)); 2) The DC-link, the grid side converter (GSC) and the associated control system (as shown in Figure 1(b)); and 3) The synchronous reference frame phase-locked loop (SRF-PLL) (as presented in Figure 2), which is used to synchronize FCWG with the external power system.

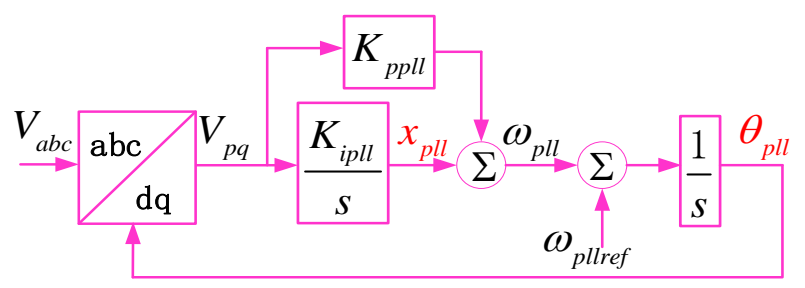

Figure 2. Block diagram of SRF-PLL.

\subsection{Configuration of FCPV}

A PV farm interconnected to a power system is shown in Figure 3, which consists of five main parts: 1) A PV generation unit, 2) The DC/DC converter and the associated control system, 3) The DC- 
link, 4) GSC and the associated control system, 5) The SRF-PLL which keeps the synchronization with the AC power system, which has the same control configuration as FCWG.

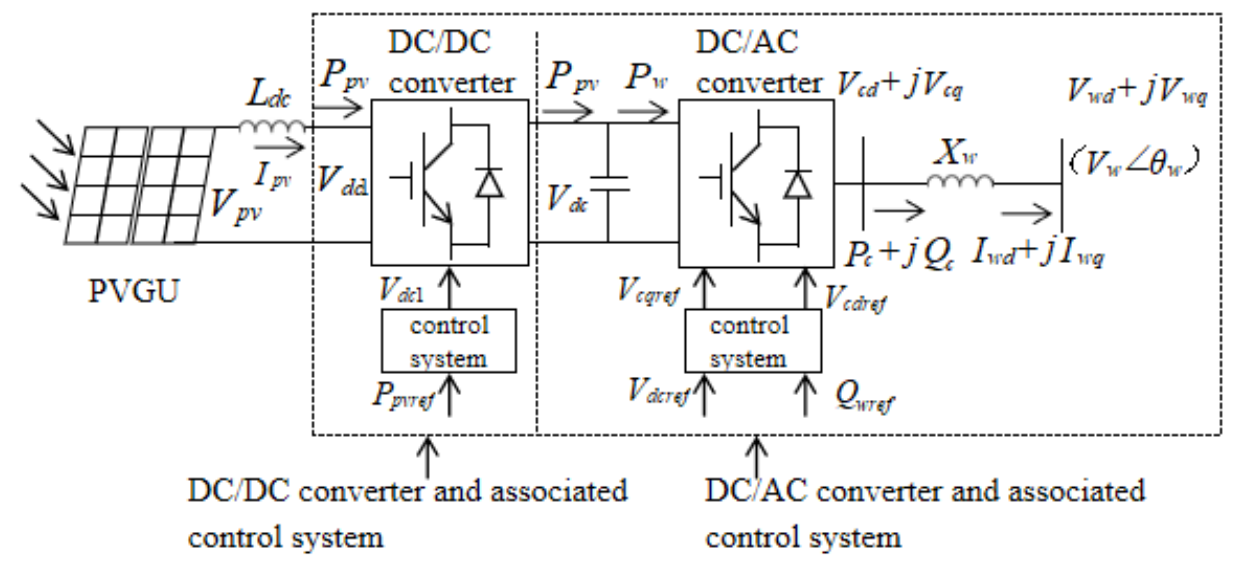

Figure 3. Configuration of a PV farm interconnected to a power system.

\section{Dynamic Models of FCWG and FCPV}

To elaborate the modal interaction mechanism, the external AC power system excludes the HRES dynamics is denoted as the open-loop system, while the entire system is the closed-loop system. Therefore, the impact of HRES system can be quantified through open-loop and closed-loop modal analyses.

\subsection{State-space Model of FCWG}

Dynamics equations of all FCWG components are derived in this section.

1) Modeling of PMSG

The PMSG can be represented by the following equations:

$$
\begin{gathered}
\left\{\begin{array}{l}
\frac{d \psi_{p s d}}{d t}=-\omega_{0} R_{p s} i_{p s d}-\omega_{0} v_{p s d}+\omega_{0} \omega_{p r} \psi_{p s q} \\
\frac{d \psi_{p s q}}{d t}=-\omega_{0} R_{p s} i_{p s q}-\omega_{0} v_{p s q}-\omega_{0} \omega_{p r} \psi_{p s q}
\end{array}\right. \\
\left\{\begin{array}{l}
\psi_{p s d}=X_{p d} i_{p s d}-\psi_{p m} \\
\psi_{p s q}=X_{p q} i_{p s q}
\end{array}\right.
\end{gathered}
$$

where $v_{p s d}$ and $v_{p s q}$ are the direct and quadrature axis voltage of stator winding, $R_{p s}$ is the stator winding resistance, $i_{p s d}$ and $i_{p s q}$ are the direct and quadrature axis current of the stator winding, $\omega_{b}$ is the base angular speed in $\mathrm{rad} / \mathrm{s}, X_{p d}$ and $X_{p q}$ are the direct and quadrature axis reactance of stator winding, $\psi_{p m}$ is the flux linkage produced by the permanent magnet. $\omega_{p r}$ is the stator electrical angular speed, defined by: $\omega_{p r}=n_{p} \omega_{m}=\omega_{m}$, where $n_{p}=1$ is the number of pole pairs of PMSG and $\omega_{m}$ is the mechanical (rotor) angular speed.

Motion equation of the wind turbine rotor

$$
H_{p r} \frac{d \omega_{p r}}{d t}=T_{p m}-T_{p e}
$$

where $H_{p r}$ is the inertia constant of the rotor, $T_{p m}$ is the mechanical torque of the wind turbine, $T_{p e}$ is the electrical torque of PMSG. 


\section{2) Modeling of MSC}

From Figure 1(a), the dynamics of MSC are derived as

$$
\left\{\begin{array}{l}
i_{p s q r e f}=K_{p p 1}\left(\omega_{p r}-\omega_{p r r e f}\right)+x_{p 1} \\
\frac{d x_{p 1}}{d t}=K_{p i 1}\left(\omega_{p r}-\omega_{p r r e f}\right) \\
\frac{d x_{p 2}}{d t}=K_{p i 2}\left(i_{p s q r e f}-i_{p s q}\right) \\
\frac{d x_{p 3}}{d t}=K_{p i 3}\left(i_{p s d r e f}-i_{p s d}\right)
\end{array}\right.
$$

It is noteworthy that the PMSG system (i.e., PMSG and MSC) is a closed-loop system. Its dynamics only related to its own state variables, do not interact with the external power system. The wind turbine does not respond to the system dynamics since it is decoupled from the power system unless additional control is introduced.

3) Modeling of DC-link

Equation of the DC-link voltage is

$$
C_{p} V_{p d c} \frac{d V_{p d c}}{d t}=P_{p s}-P_{p c}
$$

where $C_{p}$ is the capacitance, $V_{p d c}$ is DC voltage across the capacitor, $P_{p c}$ is active power output and expressed as

$$
P_{p c}=V_{p c d} I_{p c d}+V_{p c q} I_{p c q}=V_{p d} I_{p c d}+V_{p q} I_{p c q}
$$

where $I_{p c d}$ and $I_{p c q}$ are the direct and quadrature axis output current of GSC, respectively. $V_{p c d}$ and $V_{p c q}$ are the direct and quadrature axis output voltage of GSC, respectively. $V_{p d}$ and $V_{p q}$ are the direct and quadrature axis voltage at the point of common coupling (PCC), respectively.

The line voltage equations across the filter reactance $X_{p f}$ in Figure 1(b) is expressed as

$$
\left\{\begin{array}{l}
\frac{d I_{p c d}}{d t}=\frac{\omega_{0}}{X_{p f}}\left(V_{p c d}-V_{p d}\right)+\omega_{0} I_{p c q} \\
\frac{d I_{p c q}}{d t}=\frac{\omega_{0}}{X_{p f}}\left(V_{p c q}-V_{p q}\right)-\omega_{0} I_{p c d}
\end{array}\right.
$$

4) Modeling of GSC

A standard GSC configuration is shown in Figure 1(b), and the mathematic equations are derived as

$$
\left\{\begin{array}{l}
\frac{d x_{p 4}}{d t}=K_{p i 4}\left(V_{p d c}-V_{p d c r e f}\right) \\
\frac{d x_{p 5}}{d t}=K_{p i 5}\left(I_{p c d r e f}-I_{p c d}\right) \\
\frac{d x_{p 6}}{d t}=K_{p i 6}\left(Q_{p}-Q_{p r e f}\right) \\
\frac{d x_{p 7}}{d t}=K_{p i 7}\left(I_{p c q r e f}-I_{p c q}\right)
\end{array}\right.
$$

where $V_{\text {pdcref }}$ is the reference of the DC voltage controller; $Q_{\text {pref }}$ is the reference of reactive power controller; $Q_{p}$ is the reactive power output of GSC and expressed as 


$$
Q_{p}=V_{p q} I_{p c d}-V_{p d} I_{p c q}
$$

5) Modeling of PLL

From the block diagram of SRF-PLL shown in Figure 2,

$$
\left\{\begin{array}{l}
\frac{d}{d t} x_{p l l}=K_{i p l l} V_{p q} \\
\frac{d}{d t} \theta_{p l l}=x_{p l l}+K_{p p l l} V_{p q}+\omega_{p l l r e f}
\end{array}\right.
$$

By linearizing equations (1) - (10) and combining them together, the linearized state-space model of FCWG can be expressed as

$$
\left\{\begin{array}{l}
\frac{d}{d t} \Delta X_{W}=A_{W} \Delta X_{W}+B_{W} \Delta V_{W} \\
\Delta I_{W}=C_{W} \Delta X_{W}
\end{array}\right.
$$

where $\Delta X_{W}$ denotes all the state variables of FCWG (i.e., the differential state variables in equations above); $A_{W}, B_{W}, C_{W}$ are the state-space matrices after integrating all the linearized differential equations.

\subsection{State-space Model of FCPV}

1) Modeling of PV generation unit

According to the voltage-current characteristic of FCPV, the relationship between output voltage and current of a FCPV is expressed as [25].

$$
V_{p v}=\frac{N_{s} n k T}{q} \ln \left(\frac{\frac{N_{p} I_{s c} I_{r}}{100}-I_{p v}}{N_{p} I_{0}}+1\right)
$$

where $V_{p v}$ and $\mathrm{I}_{p v}$ are voltage and current output respectively; $T$ is the junction temperature, $k$ is Boltzmann's constant, $N_{s}$ and $N_{p}$ are the number of PV cells in series and parallel respectively, $q$ is the charge of electron, $n$ is the ideality factor, $I_{r}$ is the irradiance, $I_{s c}$ is the short-circuit current, $I_{0}$ is the saturation current.

Therefore, the output active power from a FCPV is shown below:

$$
P_{p v}=I_{p v} V_{p v}
$$

An inductance is used to limit the change of output current of the FCPV, and its dynamics can be derived as

$$
\frac{d I_{p v}}{d t}=\frac{\omega_{0}}{L_{d c}}\left(V_{p v}-V_{d c 1}\right)
$$

where $V_{d c 1}$ is the input DC voltage of DC/DC converter.

2) Modeling of DC/DC converter

The control structure of DC/DC converter is shown in Figure 4. DC/DC converter control system consists of two control loops, i.e., an outer active power control loop and an inner current control loop. 


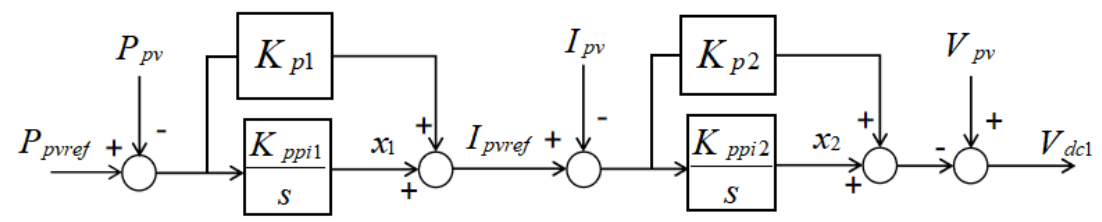

Figure 4. Control structure of DC/DC converter.

The dynamics of DC/DC converter control system can be written as

$$
\left\{\begin{array}{l}
\frac{d x_{1}}{d t}=K_{p p i 1}\left(P_{p v r e f}-P_{p v}\right) \\
\frac{d x_{2}}{d t}=K_{p p i 2}\left(I_{p v r e f}-I_{p v}\right)
\end{array}\right.
$$

where $x_{1}$ and $x_{2}$ are the state variables of PI controllers, $K_{p p i 1}$ and $K_{p 1}$ are the parameters of PI controller of the active power control, $K_{p p i 2}$ and $K_{p 2}$ are the parameters of PI controller of the current control, $P_{\text {pvref }}$ is the reference output active power and $I_{\text {pvref }}$ is the reference current.

3) Modeling of DC-link

Ignoring the power loss of converters, dynamic equation of the DC capacitor is expressed as

$$
C_{d c} V_{d c} \frac{d V_{d c}}{d t}=P_{p v}-P_{w}
$$

where $C_{d c}$ is DC capacitance, $V_{d c}$ is the voltage across capacitor, $P_{p v}$ in the injected power from PV, and $P_{w}$ is the output active power in DC-link and defined as

$$
P_{w}=V_{w d} I_{w d}+V_{w q} I_{w q}
$$

where $I_{w d}$ and $I_{w q}$ are the direct and quadrature axis output current of GSC, respectively; $V_{w d}$ and $V_{w q}$ are direct and quadrature axis voltage of low voltage bus, respectively.

Dynamics of the filter inductor are expressed as

$$
\left\{\begin{array}{l}
\frac{d I_{w d}}{d t}=\frac{\omega_{0}}{x_{w}}\left(V_{c d}-V_{w d}\right)+\omega_{0} I_{w q} \\
\frac{d I_{w q}}{d t}=\frac{\omega_{0}}{x_{w}}\left(V_{c q}-V_{w q}\right)-\omega_{0} I_{w d}
\end{array}\right.
$$

where $x_{\omega}$ is the inductance of the filter.

4) Modeling of GSC

The control structure of GSC is shown in Figure 5. GSC control system consists of four control loops, viz, 1) outer DC voltage control loop, 2) outer reactive power control loop, 3) inner quadrature axis current control loop, and 4) inner direct axis current control loop.

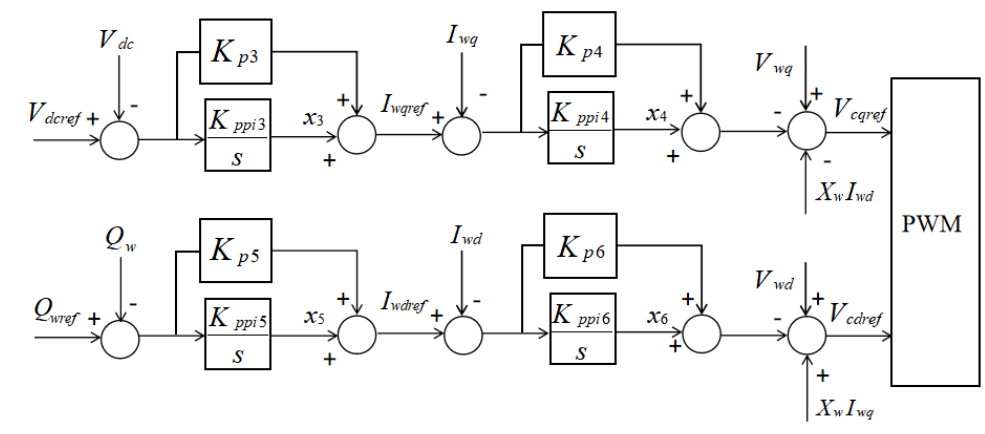

Figure 5. Control structure of GSC. 
The dynamics of GSC control system can be represented as

$$
\begin{aligned}
& \left\{\begin{array}{l}
\frac{d x_{3}}{d t}=K_{p p i 3}\left(V_{d c r e f}-V_{d c}\right) \\
\frac{d x_{4}}{d t}=K_{p p i 4}\left(I_{w q r e f}-I_{w q}\right) \\
\frac{d x_{5}}{d t}=K_{p p i 5}\left(Q_{w r e f}-Q_{w}\right) \\
\frac{d x_{6}}{d t}=K_{p p i 6}\left(I_{w d r e f}-I_{w d}\right)
\end{array}\right. \\
& Q_{w}=V_{w q} I_{w d}-V_{w d} I_{w q}
\end{aligned}
$$

where $x_{3}, x_{4}, x_{5}$ and $x_{6}$ are the state variables of PI controllers, $K_{p p i x}$ and $K_{p x}(\mathrm{x}=3,4,5,6)$ are the parameters of corresponding PI controllers shown in Figure 5; $V_{\text {dcref }}$ is the reference of DC voltage control, $I_{w d r e f}$ and $I_{w q r e f}$ are the references of inner direct and quadrature current control loops of GSC, respectively, $V_{\text {cdref }}$ and $V_{\text {cqref }}$ are the reference direct and quadrature axis output voltage of GSC, respectively, $Q_{w}$ is the injected reactive power into power systems and $Q_{w r e f}$ is the reference of reactive power control loop.

5) Modeling of SRF-PLL

The same structure of the SRF-PLL shown in Figure 2 is applied in FCPV and its dynamic are expressed as

$$
\left\{\begin{array}{l}
\frac{d}{d t} x_{p l l 2}=K_{p l l i} V_{w q} \\
\frac{d}{d t} \theta_{p l l 2}=x_{p l l 2}+K_{p l l} V_{w q}+\omega_{p l l 2 r e f}
\end{array}\right.
$$

where $x_{p l l 2}$ and $\theta_{p l l 2}$ (i.e., phase angle) are the state variables of PLL dynamics, $\omega_{\text {pll2ref }}$ is angular speed of PLL in rad/s, $K_{p l l i}$ and $K_{p l l}$ are the integral and proportional parameters of the PLL controller, respectively.

Therefore, by linearizing equations (12) - (21), the linearized state-space model of FCPV is obtained as

$$
\left\{\begin{array}{l}
\frac{d}{d t} \Delta \mathbf{X}_{\mathbf{p p} 2}=\mathbf{A}_{\mathbf{p p} 2} \Delta \mathbf{X}_{\mathbf{p p} 2}+\mathbf{B}_{\mathbf{p p} 2} \Delta \mathbf{V}_{\mathbf{w}} \\
\Delta \mathbf{I}_{\mathbf{p}}=\mathbf{C}_{\mathbf{p p} 2} \Delta \mathbf{X}_{\mathbf{p p} 2}
\end{array}\right.
$$

where $\Delta X_{p p 2}$ denotes all the state variables of FCPV; $A_{p p 2}, B_{p p 2}, C_{p p 2}$ are the state-space matrices after integrating all the linearized differential equations.

\subsection{Linearized Modeling of HRES System}

By connecting the linearized state-space models for FCWG in (11) and FCPV in (22), the linearized state-space model of an HRES system can be represented as

$$
\left\{\begin{array}{l}
\frac{d}{d t} \Delta \mathbf{X}_{R E S}=\mathbf{A}_{R E S} \Delta \mathbf{X}_{R E S}+\mathbf{B}_{R E S} \Delta \mathbf{V}_{M} \\
\Delta \mathbf{I}_{\mathbf{M}}=\mathbf{C}_{R E S} \Delta \mathbf{X}_{R E S}
\end{array}\right.
$$


where $A_{R E S}=\left[\begin{array}{cc}A_{p p v} & 0 \\ 0 & A_{w f}\end{array}\right], \boldsymbol{A}_{p p v}=\left[\begin{array}{ccc}A_{p v 1} & \cdots & 0 \\ \vdots & \ddots & \vdots \\ 0 & \cdots & A_{p v N}\end{array}\right], \boldsymbol{A}_{w f}=\left[\begin{array}{ccc}A_{w f 1} & \cdots & 0 \\ \vdots & \ddots & \vdots \\ 0 & \cdots & A_{w f M}\end{array}\right]$, $B_{R E S}=\left[\begin{array}{cc}B_{p p v} & 0 \\ 0 & B_{w f}\end{array}\right], B_{p p v}=\left[\begin{array}{ccc}B_{p v 1} & \cdots & 0 \\ \vdots & \ddots & \vdots \\ 0 & \cdots & B_{p v N}\end{array}\right], \boldsymbol{B}_{w f}=\left[\begin{array}{ccc}\boldsymbol{B}_{g p 1} & \cdots & 0 \\ \vdots & \ddots & \vdots \\ 0 & \cdots & \boldsymbol{B}_{g p M}\end{array}\right], C_{R E S}=\left[\begin{array}{cc}C_{p p v} & 0 \\ 0 & C_{w f}\end{array}\right]$, $\boldsymbol{C}_{p p v}=\left[\begin{array}{ccc}C_{p v 1} & \cdots & 0 \\ \vdots & \ddots & \vdots \\ 0 & \cdots & C_{p v N}\end{array}\right], \boldsymbol{C}_{w f}=\left[\begin{array}{ccc}C_{g p 1} & \cdots & 0 \\ \vdots & \ddots & \vdots \\ 0 & \cdots & C_{g p M}\end{array}\right] . A_{p v x}, B_{p v x}, C_{p v 1}(\mathrm{x}=1,2, \ldots, \mathrm{n})$ are state matrices of the 1 st to Nth FCPV, respectively; $\boldsymbol{A}_{\boldsymbol{g p \mathbf { x }}}, \boldsymbol{B}_{\boldsymbol{g p \mathbf { x }}}, \boldsymbol{C}_{\boldsymbol{g p \mathbf { x }}}(\mathrm{x}=1,2, . ., \mathrm{m})$ are state matrices of the 1 st to $M t h$ FCWG respectively; $\Delta \boldsymbol{V}_{\boldsymbol{M}}$ and $\boldsymbol{\Delta} \boldsymbol{I}_{\boldsymbol{M}}$ are PCC voltage and output current of the HRES system.

\subsection{Entire Inteconnected Power System}

In the open-loop power system, HRES system can be modeled as a constant power source. Assume that the state-space model for $N$ SGs in the AC power system is expressed as

$$
\left\{\begin{array}{l}
\frac{d}{d t} \Delta X_{g}=A_{g} \Delta X_{g}+B_{g} \Delta V_{g} \\
\Delta I_{g}=C_{g} \Delta X_{g}+D_{g} \Delta V_{g}
\end{array}\right.
$$

where $\quad \Delta X_{g}=\left[\Delta X_{g 1}^{T} \ldots \Delta X_{g N}^{T}\right]^{T}, \quad \Delta I_{g}=\left[\Delta I_{g 1}^{T} \ldots \Delta I_{g N}^{T}\right]^{T}, \quad \Delta V_{g}=\left[\Delta V_{g 1}^{T} \ldots \Delta V_{g N}^{T}\right]^{T}, \quad A_{g}=\operatorname{diag}\left[A_{g 1} \ldots A_{g N}\right]$ ， $B_{g}=\operatorname{diag}\left[B_{g 1} \ldots B_{g N}\right], C_{g}=\operatorname{diag}\left[C_{g 1} \ldots C_{g N}\right], D_{g}=\operatorname{diag}\left[D_{g 1} \ldots D_{g N}\right], \Delta X_{g j}^{T}, j=1,2, \ldots N$ denotes the vector of all the state variables of the $j$ th SG. $\operatorname{diag}[]$ denotes either a diagonal matrix or a block diagonal matrix.

The equation of the transmission network is expressed as

$$
\left[\begin{array}{l}
I_{g} \\
I_{M} \\
I_{N}
\end{array}\right]=\left[\begin{array}{lll}
Y_{g g} & Y_{g w} & Y_{g n} \\
Y_{w g} & Y_{w w} & Y_{w n} \\
Y_{n g} & Y_{n w} & Y_{n n}
\end{array}\right]\left[\begin{array}{c}
V_{g} \\
V_{M} \\
V_{N}
\end{array}\right]
$$

where $I_{\mathrm{g}}, V_{\mathrm{g}}$ is the SG terminal current injection and bus voltage at the connecting point; $I_{\mathrm{N}}, V_{\mathrm{N}}$ is the current injection and voltage at other buses in the network. $Y$ denotes the admittance matrix.

From (24) and (25), the open-loop power system can be derived as

$$
\left\{\begin{array}{l}
\frac{d}{d t} \Delta \mathbf{X}_{\mathbf{g}}=\mathbf{A}_{\mathbf{g s}} \mathbf{\Delta} \mathbf{X}_{\mathbf{g}}+\mathbf{B}_{\mathbf{g s}} \Delta I_{M} \\
\Delta V_{M}=\mathbf{C}_{\mathbf{g s}} \mathbf{\Delta} \mathbf{X}_{\mathbf{g}}+d_{g s} \Delta I_{M}
\end{array}\right.
$$

where $A_{g s}=A_{g}+B_{g}\left(Y_{g g N}-Y_{g w N} Y_{w w N}^{-1} Y_{w g N}-D_{g}\right)^{-1} C_{g} \quad, \quad B_{g s}=-B_{g}\left(Y_{g g N}-Y_{g w N} Y_{w w N}^{-1} Y_{w g N}-\right.$ $\left.D_{g}\right)^{-1} Y_{g w N} Y_{w w N}^{-1}, C_{g s}=-Y_{w w N}^{-1} Y_{w g N}\left(Y_{g g N}-Y_{g w N} Y_{w w N}^{-1} Y_{w g N}-D_{g}\right)^{-1} C_{g}, d_{g s}=Y_{w w N}^{-1}+Y_{w w N}^{-1} Y_{w g N}$ $\left.Y_{g g N}-Y_{g w N} Y_{w w N}^{-1} Y_{w g N}-D_{g}\right)^{-1} Y_{g w N} Y_{w w N}^{-1}$.

From (23) and (26), the closed-loop interconnected model of the power system can be derived as

$$
\frac{d}{d t}\left[\begin{array}{c}
\Delta \mathbf{X}_{\mathbf{g}} \\
\Delta \mathbf{X}_{R E S}
\end{array}\right]=\left[\begin{array}{cc}
\mathbf{A}_{\mathbf{g s}} & \mathbf{B}_{\mathbf{g s}} C_{R E S} \\
B_{R E S} \mathbf{C}_{\mathbf{g s}} & A_{R E S}+B_{R E S} d_{g S} C_{R E S}
\end{array}\right]\left[\begin{array}{c}
\Delta \mathbf{X}_{\mathbf{g}} \\
\Delta \mathbf{X}_{R E S}
\end{array}\right]
$$

\section{Methodology of Optimization Strategy}


According to the modal superposition theory in [19], modal interaction can be categorized into three types: 1) weak interaction which indicates the HRES system interacts very sightly with the AC power system and thus the interaction effect can be ignored while studying converter-driven stability; 2) modal resonance that drives two adjacent oscillation modes (i.e. one from HRES system and another from AC power system) to move against each and thus impairs the system damping and threatens converter-driven stability; and 3) modal counteraction that implies that one oscillation mode from HRES system interacts positively with the EOM of the AC power system and improves the system damping. It is worthwhile mentioning that the negative modal resonance will jeopardize converter-driven stability and thus should be avoided, while the positive modal counteraction should be taken into account when integrating an HRES system.

To facilitate the positive interaction between HRES system and AC power system, an eigenvalue shift index (ESI) is utilized to quantitively evaluate the effect of modal interaction on the critical EOM. Denote $\lambda_{\text {olsysi }}=\sigma \pm j \omega$ as the $i$ th oscillation mode of the open-loop power system, $\lambda_{\text {clsysi }}=\hat{\sigma} \pm j \widehat{\omega}$ as the ith oscillation mode of the closed-loop system. Hence, the dynamic interaction effect of the newly introduced HRES system is evaluated by ESI $=\Delta \lambda_{\text {sys }}=\lambda_{\text {clsysi }}-\lambda_{\text {olsysi }}$. According to the openloop and closed-loop models in Section 3.4, modal analyses can be applied and thus provide a quantitative calculation for ESI.

If the real part of ESI, i.e., $\operatorname{Re}(E S I)<0$, which demonstrates that the modal interaction between the critical EOM and FOM or POM is beneficial for the converter-driven stability. However, if Re (ESI) $>0$, a detrimental impact regarding modal interaction is induced and deteriorates the converter-driven stability. To tackle this negative impact, a modal interaction optimization can be implemented by tuning control parameters of the HRES system. The optimization objective, as expressed in (28) is to obtain the largest modal shift in critical EOM towards the left half complex plane.

$$
\text { Minimize } \operatorname{Re}(E S I)=\operatorname{real}\left(\Delta \lambda_{\text {sys }}\right)
$$

It should be pointed out that, the modal interaction optimization should not sacrifice the dynamics of HRES system at an unacceptable level. Since parameter tuning is performed in HRES controllers, it is necessary and available to guarantee a sufficient damping margin for HRES system. Moreover, a severe multi-mode modal resonance will be investigated in the following section and set as the base case for modal interaction optimization.

\section{Case Study}

\subsection{Introduction of Test System}

An IEEE 16-machine 68-bus system with a HRES system connected at bus 8 is illustrated in Figure 6. Operating condition are set as: $S_{b}=100 \mathrm{MVA}, V_{\text {bus } 69}=1.015$ p.u., $V_{\text {bus } 70}=1.002$ p.u. 


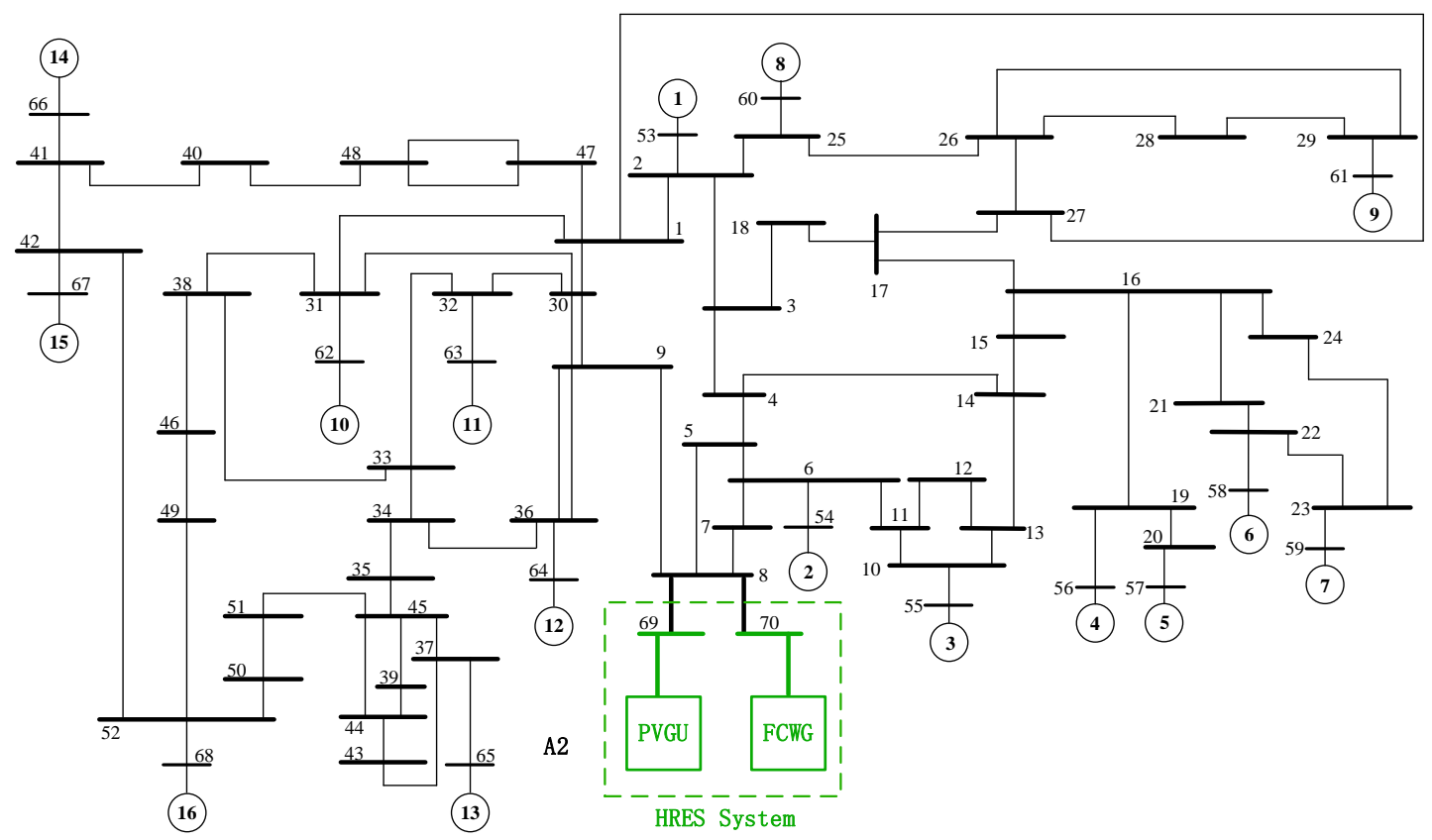

Figure 6. Configuration of a test IEEE power system integrated with an HRES system.

To begin with, open-loop modal analyses of the examined power systems with different wind power and PV solar energy penetration level are performed. Followed by closed-loop modal resonance analyses of the closed-loop system and time-domain simulations as a supplementary verification. To mitigate the detrimental effect caused by modal resonance, the optimization strategy is further adopted as well.

\subsection{Modal Analyses considering Different Renewable Energy Penetration Levels}

Based on the linearized state-space model the state matrix in equation (26), the critical EOM of the open-loop power systems can be calculated, as shown in Table 1. The critical open-loop EOM of the examined power systems is slightly affected by different constant injected active power ignoring the dynamic interaction of PMSG and FCPV. It is found that the real part of EOM, i.e., $\operatorname{real}\left(\lambda_{\text {EOM }}\right) \leq$ 0 and oscillation frequency is around $0.55 \mathrm{~Hz}$. With increasing active power injection, a very slight change occurs in the real part of the critical EOM while damping ratio almost stay at 0.0086 .

Table 1. Open-loop modal analysis regarding different renewable energy penetration levels

\begin{tabular}{ccccc}
\hline $\begin{array}{c}\text { Active power from FCWG } \\
\text { and FCPV (MW) }\end{array}$ & $\begin{array}{c}\text { Critical open-loop EOM } \\
\left(\lambda_{\text {opsys }}\right)\end{array}$ & Frequency(Hz) & $\begin{array}{c}\text { Damping } \\
\text { ratio }\end{array}$ & ELCR \\
\hline 0,0 & $-0.0303 \pm j 3.5050$ & 0.5578 & 0.0086 & 27.6935 \\
\hline 10,10 & $-0.0300 \pm j 3.5075$ & 0.5582 & 0.0086 & 27.8252 \\
\hline 20,20 & $-0.0298 \pm j 3.5099$ & 0.5586 & 0.0085 & 27.9571 \\
\hline 40,30 & $-0.0295 \pm j 3.5135$ & 0.5592 & 0.0084 & 28.1550 \\
\hline \hline
\end{tabular}


Table 2. Closed-loop modal analysis regarding different renewable energy penetration levels

\begin{tabular}{|c|c|c|c|c|}
\hline $\begin{array}{c}\text { Active power from FCWG } \\
\text { and FCPV (MW) }\end{array}$ & $\begin{array}{c}\text { Closed-loop EOM } \\
\lambda_{\text {clsys }}\end{array}$ & Frequency $(\mathrm{Hz})$ & $\begin{array}{l}\text { Damping } \\
\text { ratio }\end{array}$ & ELCR \\
\hline 0,0 & $-0.0303 \pm j 3.5050$ & 0.5578 & 0.0086 & 27.6935 \\
\hline 10,10 & $-0.2463 \pm j 3.5412$ & 0.5636 & 0.0694 & 1.0375 \\
\hline 20,20 & $-0.2323 \pm j 3.5406$ & 0.5635 & 0.0655 & 1.0970 \\
\hline 40,30 & $-0.2155 \pm j 3.5438$ & 0.5640 & 0.0607 & 1.1640 \\
\hline
\end{tabular}

Table 3. Modal resonance analysis of closed-loop FOM (wind power)

\begin{tabular}{|c|c|c|c|}
\hline $\begin{array}{l}\text { Active power from FCWG } \\
\qquad(\mathrm{MW})\end{array}$ & $\begin{array}{c}\text { Closed-loop FOM } \\
\lambda_{\text {clpmsg }}\end{array}$ & Frequency $(\mathrm{Hz})$ & Damping ratio \\
\hline 10 & $-0.0186 \pm j 3.3819$ & 0.5382 & 0.0055 \\
\hline 20 & $-0.0178 \pm j 3.3825$ & 0.5383 & 0.0052 \\
\hline 40 & $-0.0154 \pm j 3.3839$ & 0.5386 & 0.0045 \\
\hline
\end{tabular}

Table 4. Modal resonance analysis of closed-loop POM (PV)

\begin{tabular}{cccc}
\hline \hline $\begin{array}{c}\text { Active power from } \\
\text { FCPV(MW) }\end{array}$ & Closed-loop POM $\lambda_{\text {clpv }}$ & Frequency(Hz) & Damping ratio \\
\hline 10 & $0.1919 \pm j 3.5109$ & 0.5588 & -0.0546 \\
\hline 20 & $0.1807 \pm j 3.4929$ & 0.5559 & -0.0517 \\
\hline 30 & $0.1625 \pm j 3.4705$ & 0.5523 & -0.0468 \\
\hline \hline
\end{tabular}

Through participation factor evaluation, it can be found that the closed-loop resonance modes with oscillation frequencies at around $0.53 \mathrm{~Hz}$ and $0.55 \mathrm{~Hz}$, which are mainly dominated by PLL dynamics of FCWG and FCPV, respectively. Specifically, state variables related to PLL dynamics (i.e., $\left.\Delta x_{p l l}, \Delta \theta_{p l l}, \Delta x_{p l l 2}, \Delta \theta_{p l l 2}\right)$ and electromechanical dynamics (i.e., $\left.\Delta \omega_{K}, \Delta \delta_{K},(K=1,2 \ldots 16)\right)$ are the most active in these three closed-loop hybrid resonance modes.

As shown in Table 2, real parts of all the critical closed-loop EOMs are negative, $\operatorname{real}\left(\lambda_{\text {clsys }}\right) \leq$ 0 . Compared with the critical open-loop EOM, the critical closed-loop EOM $\lambda_{\text {clsys }}$ shifts towards the left half complex plane and becomes more stable as the ELCR decreases significantly. This is mainly due to the impact of modal interaction with FCWG and FCPV.

In Table 3 , the real part of the closed-loop FOM are negative, $\operatorname{real}\left(\lambda_{\text {clpmsg }}\right) \leq 0$, while it is highly possible for FCWG to lose its converter-driven stability although all FOMs still remain stable. Compared with the critical open-loop FOM, closed-loop FOM $\lambda_{\text {clpmsg }}$ shifts towards the unstable direction. Meanwhile, oscillation frequency increases slightly while damping ratio decreases slightly. 
It is also worth mentioning that, in Table 4, the real part of the closed-loop POM is positive, real $\left(\lambda_{\text {clpv }}\right) \geq 0$, which indicates POM deteriorates dramatically due to modal resonance. Compared with the critical open-loop POM, closed-loop POM $\lambda_{\text {clpv }}$ moves towards the right half complex plane and becomes unstable. Meanwhile, when HRES penetrates at a higher level, the closed-loop EOM $\lambda_{\text {clsys }}$ shifts towards right half complex plane, and ELCR varies as well.

Modal analyses regarding critical oscillation modes (viz, EOM, FOM and POM) in the open-loop and closed-loop system are demonstrated in Table $5 \sim$ Table 7 . Accordingly, eigenvalue shifts due to modal resonance is shown in Figure 7 , in which $\lambda_{\text {olsysK }}$, and $\lambda_{\text {clsys }}(K=1,2 \ldots 4)$ are the open-loop and closed-loop EOMs of external AC power system respectively; $\lambda_{\text {olpmsgk }}$ and $\lambda_{\text {clpmsgk }}(K=$ $1,2 \ldots 4)$ are the open-loop and closed-loop FOMs respectively; $\lambda_{\text {olpvk }}$ and $\lambda_{\text {clpvk }}(K=1,2 \ldots 4)$ are the open-loop and closed-loop POMs respectively.

Table 5. Eigenvalues of system EOM with different HRES levels

\begin{tabular}{cccc}
\hline $\begin{array}{c}\text { Active power from FCWG } \\
\text { and FCPV (MW) }\end{array}$ & $\begin{array}{c}\text { Critical closed-loop } \\
\text { EOM } \lambda_{\text {clsys }}\end{array}$ & $\begin{array}{c}\text { Critical open-loop } \\
\text { EOM } \lambda_{\text {clsys }}\end{array}$ & ESI \\
\hline 10,10 & $-0.2463 \pm j 3.5412$ & $-0.0300 \pm j 3.5075$ & $-0.2163 \pm j 0.0337$ \\
\hline 20,20 & $-0.2323 \pm j 3.5406$ & $-0.0298 \pm j 3.5099$ & $-0.2025 \pm j 0.0307$ \\
\hline 40,30 & $-0.2155 \pm j 3.5438$ & $-0.0295 \pm j 3.5135$ & $-0.1860 \pm j 0.0303$ \\
\hline \hline
\end{tabular}

Table 6. Eigenvalues of FOM (wind power)

\begin{tabular}{cccc}
\hline $\begin{array}{c}\text { Active power from FCWG } \\
(\mathrm{MW})\end{array}$ & $\begin{array}{c}\text { Closed-loop FOM } \\
\left(\lambda_{\text {clpmsg }}\right)\end{array}$ & $\begin{array}{c}\text { Critical open-loop } \\
\text { FOM }\left(\lambda_{\text {oppms }}\right)\end{array}$ & ESI \\
\hline 10 & $-0.0186 \pm j 3.3819$ & $-0.0245 \pm j 3.4686$ & $0.0059 \pm j 0.0867$ \\
\hline 20 & $-0.0178 \pm j 3.3825$ & $-0.0242 \pm j 3.4699$ & $0.0064 \pm j 0.0874$ \\
\hline 40 & $-0.0154 \pm j 3.3839$ & $-0.0237 \pm j 3.4724$ & $0.0083 \pm j 0.0885$ \\
\hline \hline
\end{tabular}

Table 7. Eigenvalues of POM (PV)

\begin{tabular}{cccc}
\hline \hline $\begin{array}{c}\text { Active power from FCPV } \\
(\mathrm{MW})\end{array}$ & Closed-loop POM $\lambda_{\text {clpv }}$ & $\begin{array}{c}\text { Critical open-loop } \\
\text { POM } \lambda_{\text {oppv }}\end{array}$ & ESI \\
\hline 10 & $0.1919 \pm j 3.5109$ & $-0.0267 \pm j 3.5023$ & $0.2186 \pm j 0.0086$ \\
\hline 20 & $0.1807 \pm j 3.4929$ & $-0.0324 \pm j 3.4698$ & $0.2131 \pm j 0.0231$ \\
\hline 30 & $0.1625 \pm j 3.4705$ & $-0.0377 \pm j 3.4338$ & $0.2002 \pm j 0.0367$ \\
\hline \hline
\end{tabular}




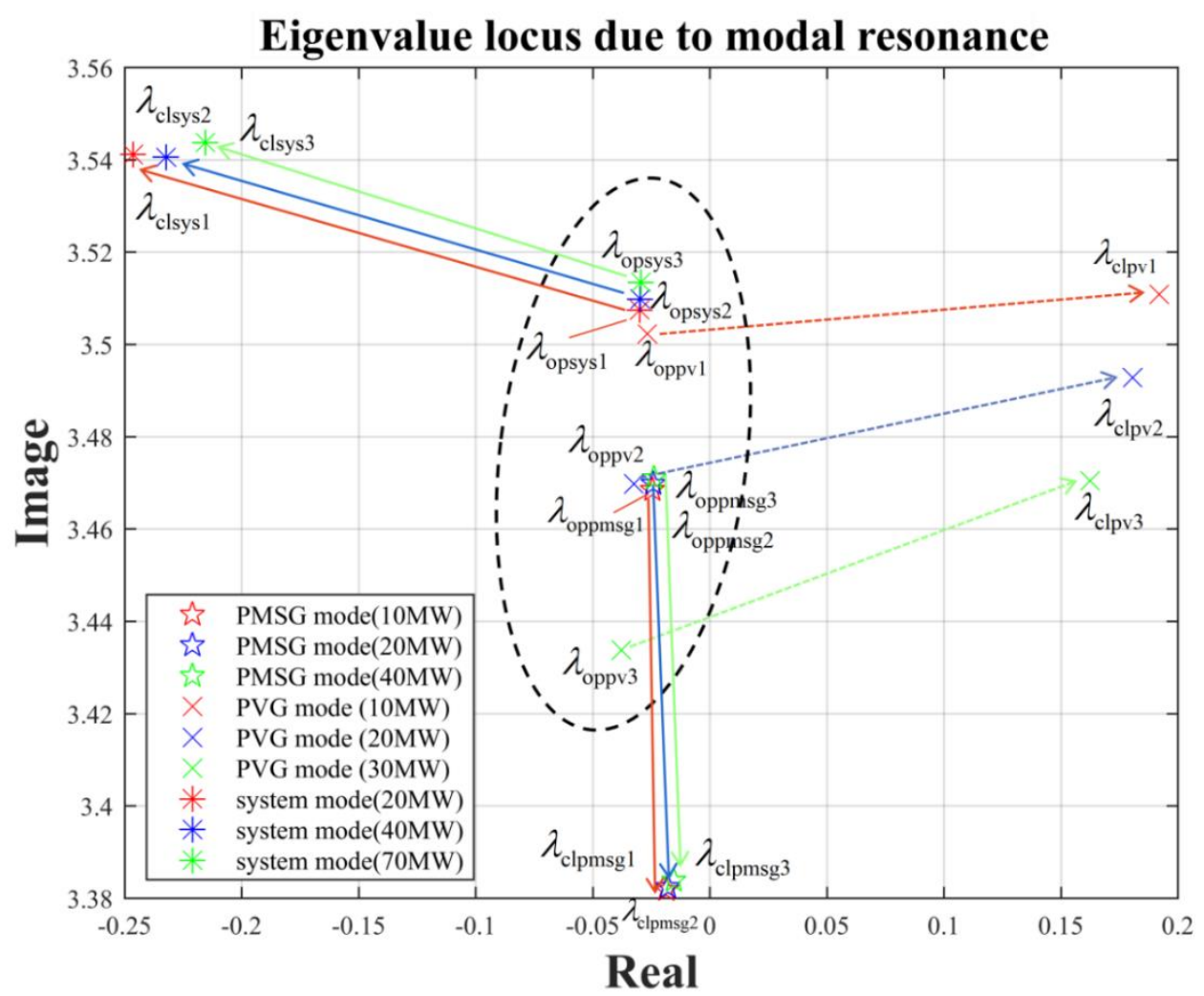

Figure 7. Modal shifts due to modal resonance.

To verify modal analysis results and further illustrate converter-driven stability visually, timedomain simulations are carried out are shown in Figure 8 Figure 13. The simulation condition is set as: a three-phase to earth short circuit occurs at Bus 2 at $\mathrm{t}=0.1 \mathrm{~s}$, and subsequently clears after $100 \mathrm{~ms}$.

Due to strong modal resonance, the closed-loop power system become unstable, SGs gradually lose synchronism and the system collapses eventually. Therefore, it is necessary to take measures to mitigate the detrimental modal resonance conditions.
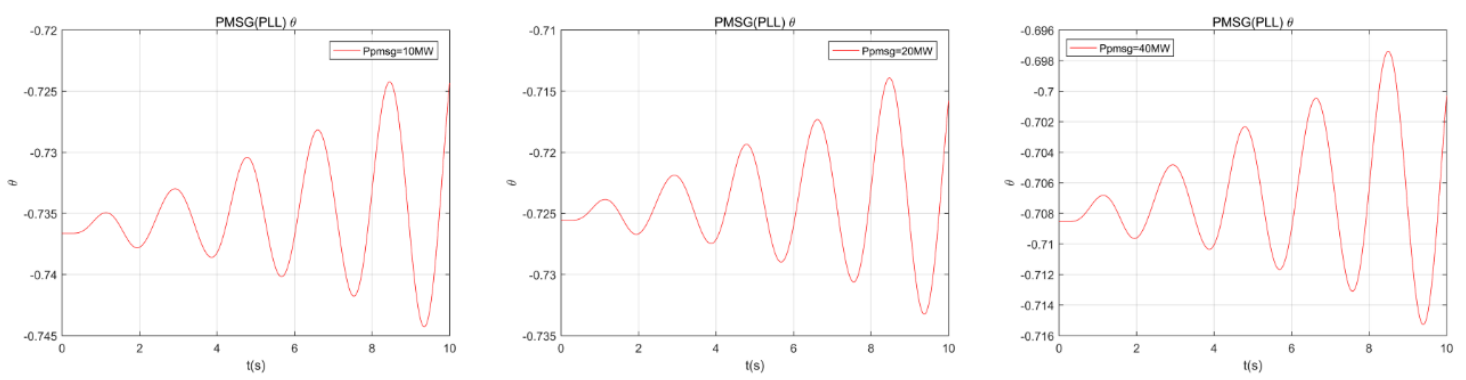

Figure 8. Phase angle of FCWG PLL with different active power outputs.
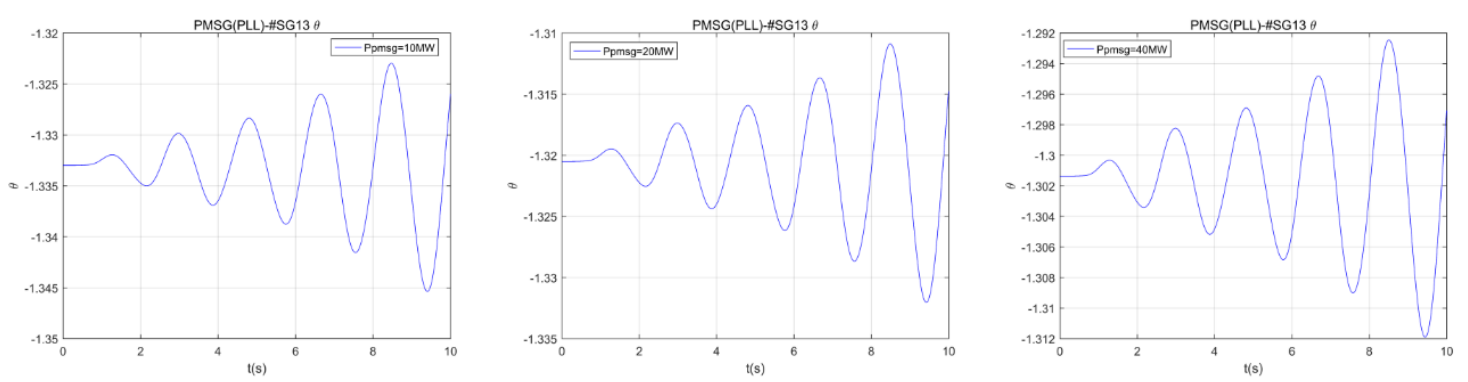

Figure 9. Phase angle difference between PMSG PLL and 13th SG. 

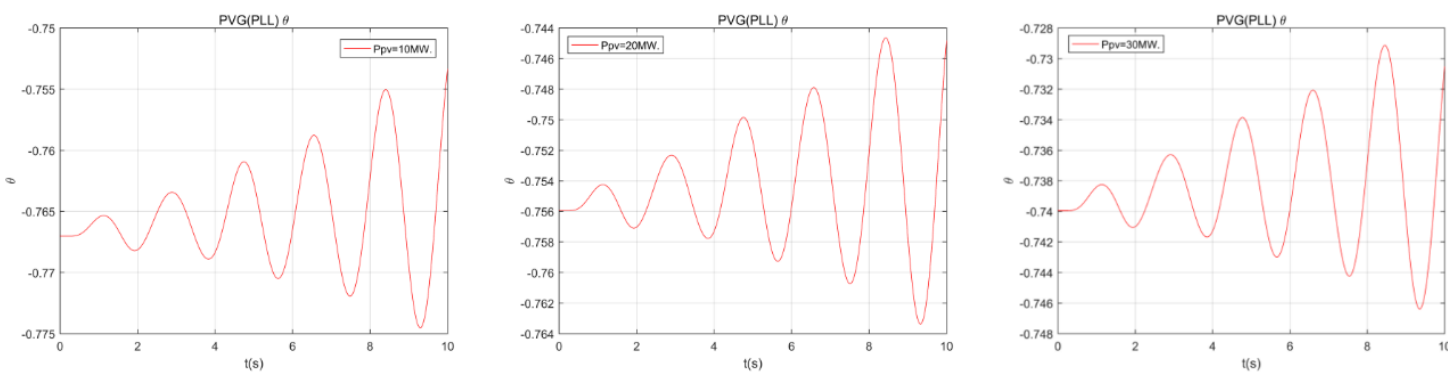

Figure 10. Phase angle of FCPV PLL with different active power outputs.
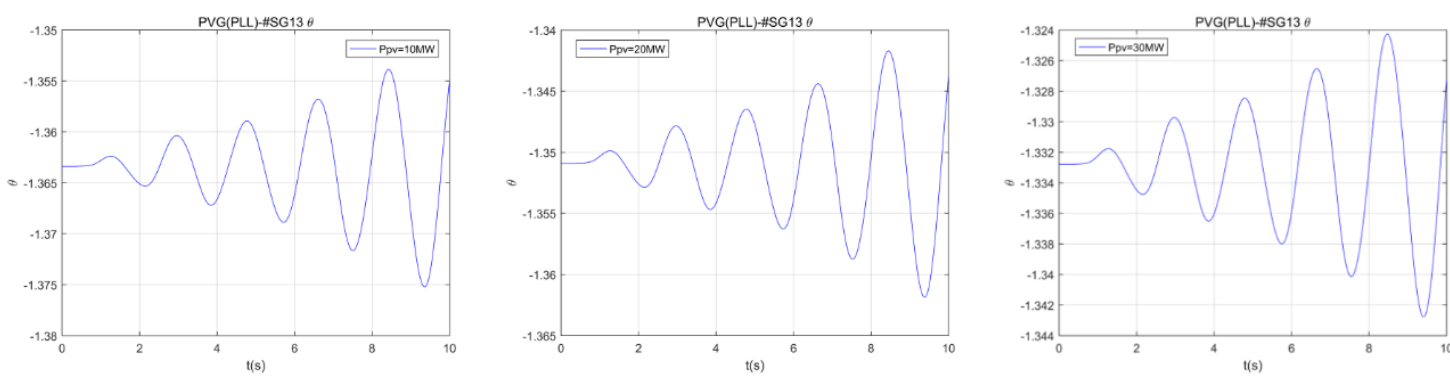

Figure 11. Phase angle difference between FCPV PLL and 13th SG.
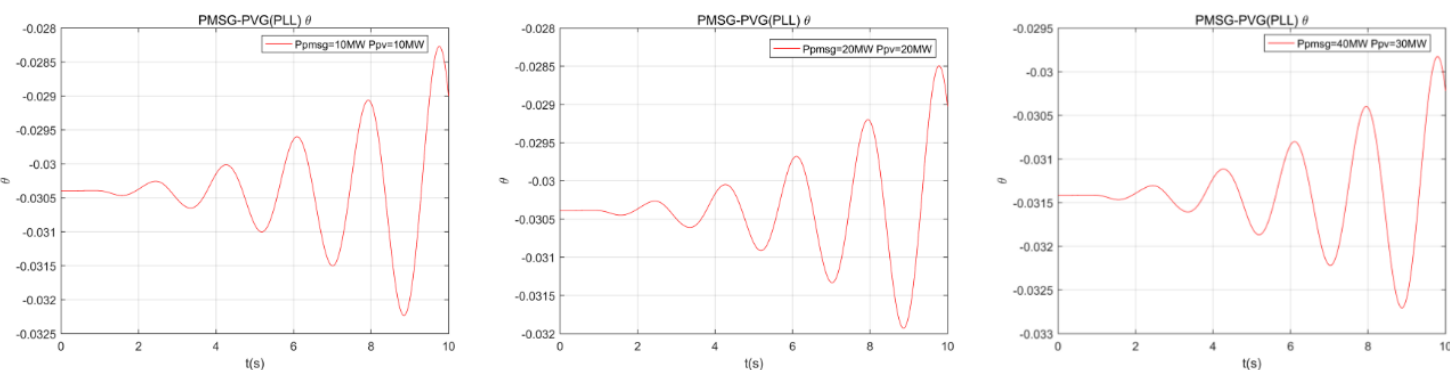

Figure 12. Phase angle difference between PLLs.
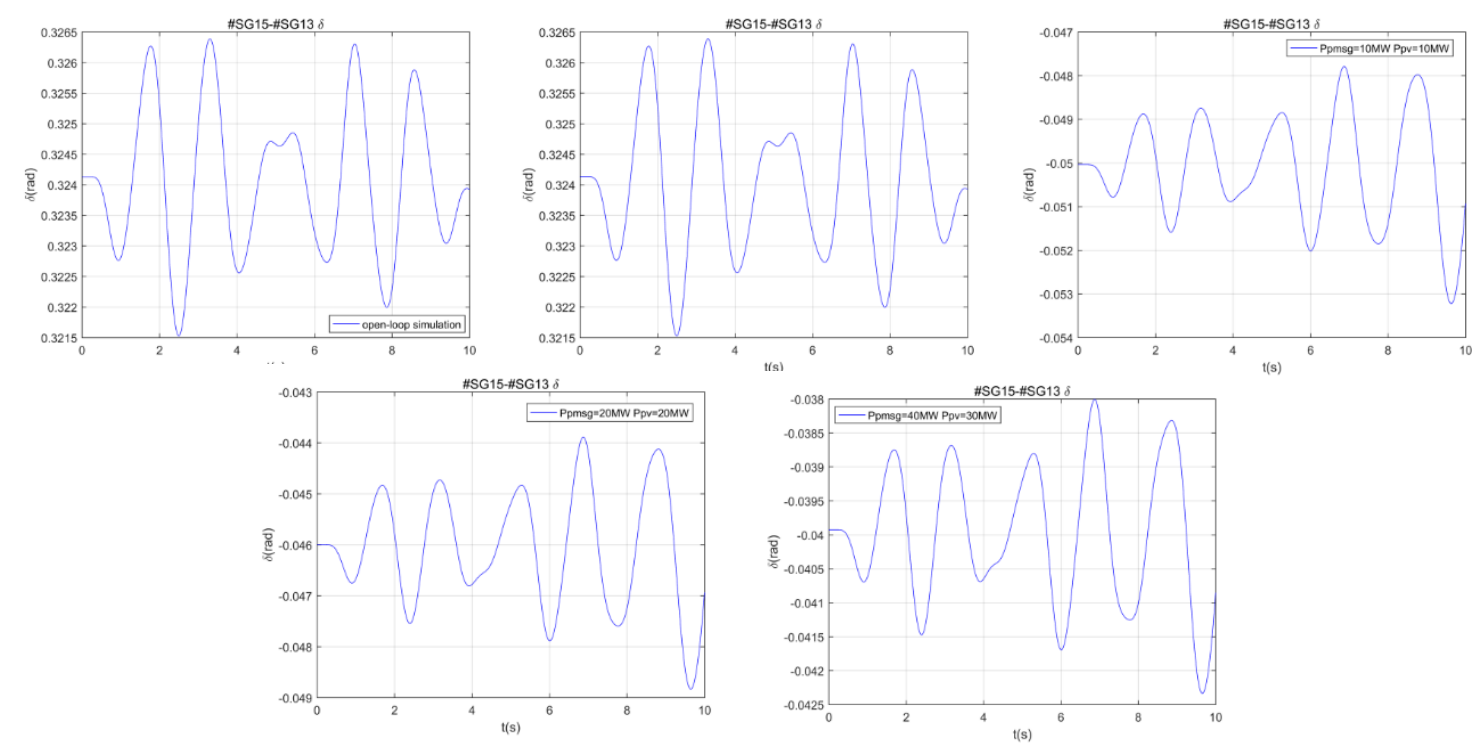

Figure 13. Phase angle difference between 13th SG and 15th SG.

\subsection{Modal Resonance Mechanism Discussion}

For the open-loop modal analysis of external AC power system, with the increasing active power injection, the critical open-loop EOM is slightly affected by different constant injected active power 
when ignoring the dynamic interaction of the HRES system. It is also found that damping of FOM degrades while that of POM improves.

For the closed-loop modal analysis, the overall impact of HRES integration is evaluated, considering both the power flow impact and dynamic interactions. Strong modal resonance occurs when the critical open-loop FOM and POM are approached to the critical open-loop EOM.

The approached critical oscillation modes of HRES system (i.e., FOM of FCWG and POM of FCPV) and system EOM are merged into three closed-loop hybrid modes and interact among themselves. The POM and critical EOM will shift towards opposite directions, while FOM moves slightly downwards. Moreover, FCPV loses converter-driven stability while critical EOM gains more damping as well as converter-driven stability with increased wind power and photovoltaic solar energy penetration level.

\subsection{Modal Interaction Optimization to Enhance Converter-driven Stablity}

A modal interaction optimization strategy is implemented to mitigate the detrimental effect of modal resonance and enhance the converter-driven stability. By tuning parameters of FCWG and FCPV, the critical open-loop FOM and POM can be moved away from critical open-loop EOM of the external AC power system. As a result, the strong modal resonance is eliminated. The modified parameters are listed in Table 8. The modal analysis results of the closed-loop system are shown in Table 9.

Compared with the open-loop FOM and POM, the modified closed-loop FOM $\left(\lambda_{\text {clpmsg }}\right)$ and closed-loop POM $\left(\lambda_{\text {clpv }}\right)$ shift towards right half complex plane and remain stable. Compared with the original power system with inadequate damping, the critical closed-loop EOM after optimization gains better converter-driven stability and significantly improved damping. The ELCR of EOM also implies the effect of modal interaction of HRES dynamics. The detrimental effect of modal resonance is mitigated with effective optimization strategy with modified parameters of HRES system, including the parameters of PI controllers and PLLs.

Table 8. Parameter Optimization of FCWG and FCPV

\begin{tabular}{ccc}
\hline Type & Original control parameters & Modified control parameters \\
\hline FCWG & $K_{\text {ppll }}=0.04, K_{\text {ipll }}=11.5$ & $K_{p p l l}=1.38, K_{\text {ipll }}=11.2$ \\
\hline $\begin{array}{c}\text { Critical open- } \\
\text { loop FOM } \\
\text { (damping ratio) }\end{array}$ & $-0.0245 \pm j 3.4686$ & $-0.7252 \pm j 3.3501$ \\
& $(0.71 \%)$ & $(21.16 \%)$ \\
FCPV & $K_{p 5}=2.16, K_{p p i 5}=0.006, K_{p 6}=0.4$, & $K_{p 5}=0.016, K_{p p i 5}=32, K_{p 6}=0.145$, \\
& $K_{p p i 6}=8, K_{p l l}=0.058, K_{p l l i}=12$ & $K_{p p i 6}=0.61, K_{p l l}=19.8, K_{p l l i}=48.98$ \\
\hline $\begin{array}{c}\text { Critical open- } \\
\text { loop POM }\end{array}$ & $-0.0267 \pm j 3.5023$ & $-1.3032 \pm j 3.1559$ \\
$($ damping ratio $)$ & $(0.71 \%)$ & $(38.17 \%)$ \\
\hline \hline
\end{tabular}


Table 9. Modal analysis of closed-loop system after optimization with highest penetration level

\begin{tabular}{ccccc}
\hline \hline $\begin{array}{c}\text { Active power from FCWG }(40 \mathrm{MW}) \\
\text { and FCPV }(30 \mathrm{MW})\end{array}$ & Eigenvalue & Frequency $(\mathrm{Hz})$ & $\begin{array}{c}\text { Damping } \\
\text { ratio }\end{array}$ & ELCR \\
\hline Closed-loop EOM $\left(\lambda_{\text {clsys }}\right)$ & $-0.2755 \pm j 3.8969$ & 0.6202 & 0.0705 & 1.0266 \\
\hline Closed-loop FOM $\left(\lambda_{\text {clpmsg }}\right)$ & $-0.6633 \pm j 3.2578$ & 0.5185 & 0.1995 & $\mathrm{NA}$ \\
\hline Closed-loop POM $\left(\lambda_{\text {clpv }}\right)$ & $-0.3464 \pm j 3.7836$ & 0.6022 & 0.0912 & $\mathrm{NA}$ \\
\hline \hline
\end{tabular}

Time-domain simulations are also performed to verify above analyses. At $t=0.1 \mathrm{~s}$, a three-phase to earth short circuit occurs at bus 2 , and subsequently clears after $100 \mathrm{~ms}$. From the simulation results in Figure 14, the dynamic performance of the modified interconnected system is greatly improved. Therefore, the implemented optimization strategy is effective for reinforcing the converter-driven stability.
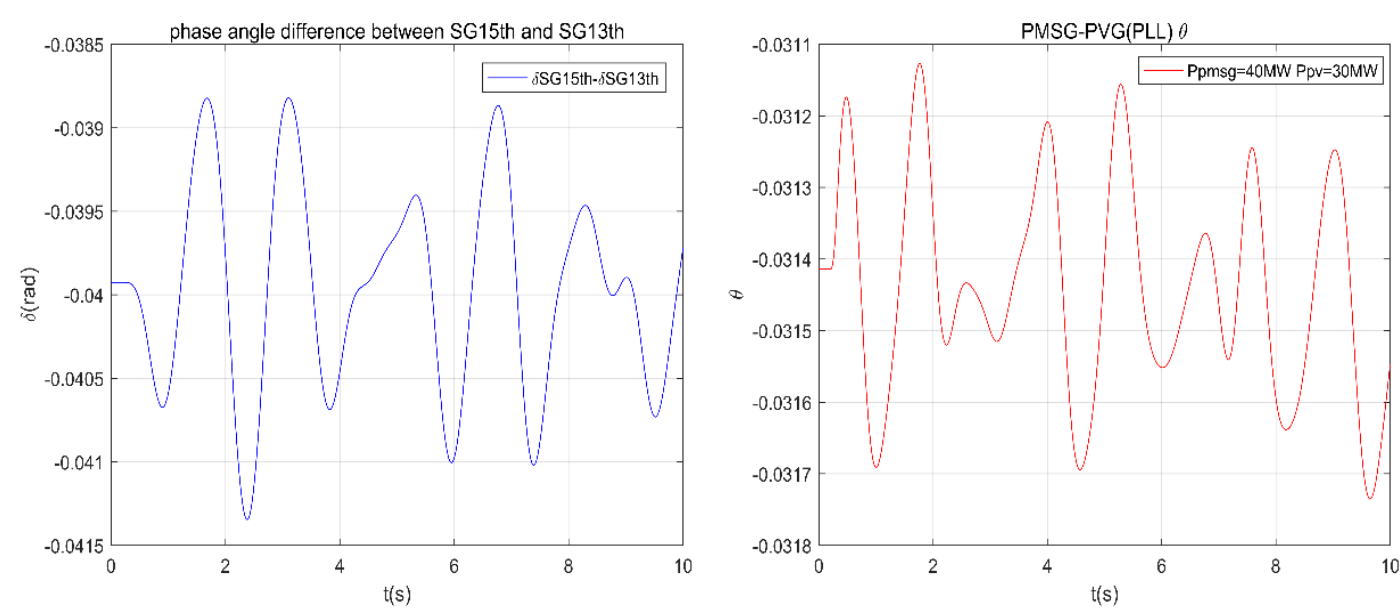

Figure 14 Phase angle difference with optimized parameters.

\section{Conclusion}

In this paper, an IEEE benchmark power system with a HRES system is investigated regarding the modal interaction between each other. The integration of HRES system not only affects the power flow, but also interacts with the external AC power system. Particularly, when modal resonance happens, the critical system EOM will be forced to move towards the right half complex plane, and thus threat the converter-driven stability. An extreme condition with three closed-loop oscillation modes is examined to evaluate the consequence of strong modal resonance. One of the critical modes becomes unstable and further propagates in the external AC power system.

To prevent this adverse phenomenon, a modal interaction optimization strategy is implemented. The converter-driven stability is significantly enhanced after relocating critical modes of the HRES system and meliorating its modal interaction with the AC power system. Consistent with modal analyses, simulation results further substantiate that the groups of SGs can maintain synchronism in large disturbance conditions after parameter optimization in the HRES system.

Author Contributions: J.L. completed the methodology, theory, and wrote the paper. Y.Z conducted data analysis, simulations, and validation. S.B. supervised the research throughout, acquired funding, coordinated 
the project, and revised \& edited the paper. All authors have read and agreed to the published version of the manuscript.

\section{Funding:}

Acknowledgments: The authors would like to acknowledge the support from National Natural Science Foundation of China for the Research Project (52077188), Guangdong Science and Technology Department for the Research Project (2019A1515011226), Hong Kong Research Grant Council for the Research Projects (25203917), (15200418) and (15219619), and Department of Electrical Engineering, The Hong Kong Polytechnic University for the Start-up Fund Research Project (1-ZE68).

Conflicts of Interest: The authors declare no conflict of interest.

\section{References}

1. Quintero, J.; Vittal, V.; Heydt, G. T.; Zhang, H., The Impact of Increased Penetration of Converter ControlBased Generators on Power System Modes of Oscillation. IEEE Trans. Power Syst. 2014, 29, (5), 2248-2256.

2. Luo, J.; Bu, S.; Zhu, J.; Chung, C. Y., Modal Shift Evaluation and Optimization for Resonance Mechanism Investigation and Mitigation of Power Systems Integrated With FCWG. IEEE Trans. Power Syst. 2020, 35, (5), 4046-4055.

3. Elliott, R. T.; Ellis, A.; Pourbeik, P.; Sanchez-Gasca, J. J.; Senthil, J.; Weber, J. In Generic photovoltaic system models for WECC - A status report, 2015 IEEE Power \& Energy Society General Meeting, 26-30 July 2015, 2015; 2015; pp 1-5.

4. Hatziargyriou, N.; Milanović, J.; Rahmann, C.; Ajjarapu, V.; Cañizares, C.; Erlich, I.; Hill, D.; Hiskens, I.; Kamwa, I.; Pal, B., Stability definitions and characterization of dynamic behavior in systems with high penetration of power electronic interfaced technologies. IEEE PES Technical Report PES-TR77 2020, 42.

5. Adams, J.; Pappu, V. A.; Dixit, A. In Ercot experience screening for Sub-Synchronous Control Interaction in the vicinity of series capacitor banks, 2012 IEEE Power and Energy Society General Meeting, 22-26 July 2012, 2012; 2012; pp 1-5.

6. Liu, H.; Xie, X.; Gao, X.; Liu, H.; Li, Y., Stability Analysis of SSR in Multiple Wind Farms Connected to Series-Compensated Systems Using Impedance Network Model. IEEE Trans. Power Syst. 2018, 33, (3), 31183128.

7. Luo, J.; Bu, S.; Chung, C. Y., Design and Comparison of Auxiliary Resonance controllers for Mitigating Modal Resonance of Power Systems Integrated with Wind Generation. IEEE Trans. Power Syst. 2021, 1-1.

8. Zhan, Y.; Xie, X.; Liu, H.; Liu, H.; Li, Y., Frequency-Domain Modal Analysis of the Oscillatory Stability of Power Systems With High-Penetration Renewables. IEEE Trans. Sustainable Energy 2019, 10, (3), 1534-1543.

9. Du, W.; Chen, X.; Wang, H. F., Power System Electromechanical Oscillation Modes as Affected by Dynamic Interactions From Grid-Connected PMSGs for Wind Power Generation. IEEE Trans. Sustainable Energy 2017, 8, (3), 1301-1312.

10. Du, W.; Bi, J.; Wang, H., Damping Degradation of Power System Low-Frequency Electromechanical Oscillations Caused by Open-Loop Modal Resonance. IEEE Trans. Power Syst. 2018, 33, (5), 5072-5081.

11. Luo, J.; Bu, S.; Zhu, J., Transition from Electromechanical Dynamics to Quasi-Electromechanical Dynamics Caused by Participation of Full Converter-Based Wind Power Generation. Energies 2020, 13, (23), 6270.

12. Zhou, J. Z.; Ding, H.; Fan, S.; Zhang, Y.; Gole, A. M., Impact of Short-Circuit Ratio and Phase-Locked-Loop Parameters on the Small-Signal Behavior of a VSC-HVDC Converter. IEEE Trans. Power Delivery 2014, 29, (5), 2287-2296. 
13. Meegahapola, L. G.; Bu, S.; Wadduwage, D. P.; Chung, C. Y.; Yu, X., Review on Oscillatory Stability in Power Grids With Renewable Energy Sources: Monitoring, Analysis, and Control Using Synchrophasor Technology. IEEE Trans. Ind. Electron. 2021, 68, (1), 519-531.

14. Morató, J.; Knüppel, T.; Østergaard, J., Residue-Based Evaluation of the Use of Wind Power Plants With Full Converter Wind Turbines for Power Oscillation Damping Control. IEEE Trans. Sustainable Energy 2014, 5, (1), 82-89.

15. Knüppel, T.; Nielsen, J. N.; Jensen, K. H.; Dixon, A.; Østergaard, J., Power Oscillation Damping Capabilities of Wind Power Plant with Full Converter Wind Turbines Considering its Distributed and Modular Characteristics. IET Renewable Power Gener. 2013, 7, (5), 431-442.

16. Haque, M. E.; Negnevitsky, M.; Muttaqi, K. M. In A Novel Control Strategy for a Variable Speed Wind Turbine with a Permanent Magnet Synchronous Generator, 2008 IEEE Industry Applications Society Annual Meeting, 5-9 Oct. 2008, 2008; 2008; pp 1-8.

17. Jamehbozorg, A.; Radman, G., Small Signal Analysis of Power Systems With Wind and Energy Storage Units. IEEE Trans. Power Syst. 2015, 30, (1), 298-305.

18. Luo, J.; Bu, S.; Zhu, J., A Novel PMU-based Adaptive Coordination Strategy to Mitigate Modal Resonance between Full Converter-based Wind Generation and Grids. IEEE Journal of Emerging and Selected Topics in Power Electronics 2020, Early Access.

19. Luo, J.; Bu, S.; Teng, F., An Optimal Modal Coordination Strategy based on Modal Superposition Theory to Mitigate Low Frequency Oscillation in FCWG Penetrated Power Systems. Int. J. Electr. Power Energy Syst. 2020, 120, 105975.

20. Gautam, D.; Vittal, V.; Harbour, T., Impact of Increased Penetration of DFIG-Based Wind Turbine Generators on Transient and Small Signal Stability of Power Systems. IEEE Trans. Power Syst. 2009, 24, (3), 1426-1434.

21. Slootweg, J. G.; Kling, W. L., The impact of large scale wind power generation on power system oscillations. Electr. Power Syst. Res. 2003, 67, (1), 9-20.

22. Wen, B.; Boroyevich, D.; Burgos, R.; Mattavelli, P.; Shen, Z., Analysis of D-Q Small-Signal Impedance of Grid-Tied Inverters. IEEE Trans. Power Electron. 2016, 31, (1), 675-687.

23. Wang, L.; Lin, T.-C., Dynamic stability and transient responses of multiple grid-connected PV systems. In 2008 IEEE/PES Transmission and Distribution Conference and Exposition, pp 1-6.

24. Teng, Y.; Zhang, X.; Fan, C.; Chen, X.; Zhang, R., Resonance Risk in Infirm-interconnected Grid Considering Photovoltaic Devices. In 2018 International Conference on Power System Technology (POWERCON), pp 10041011.

25. Bi, J. T.; Du, W.; Wang, H. F., Aggregated dynamic model of grid-connected PV generation farms. 2015.

(C) 2020 by the authors. Submitted for possible open access publication under the terms and conditions of the Creative Commons Attribution (CC BY) license (http://creativecommons.org/licenses/by/4.0/). 